Bond University

Research Repository

\title{
Negotiating with difficult people
}

Wade, John

Published in:

Faulkner Law Review

\section{Licence:}

Unspecified

Link to output in Bond University research repository.

Recommended citation(APA):

Wade, J. (2011). Negotiating with difficult people. Faulkner Law Review, 2(1), 221-246.

\section{General rights}

Copyright and moral rights for the publications made accessible in the public portal are retained by the authors and/or other copyright owners and it is a condition of accessing publications that users recognise and abide by the legal requirements associated with these rights.

For more information, or if you believe that this document breaches copyright, please contact the Bond University research repository coordinator. 


\section{Bond University}

\section{ePublications@bond}

Law Faculty Publications

Faculty of Law

8-1-2009

\section{Negotiating with difficult people}

John Wade

Bond University, john_wade@bond.edu.au

Follow this and additional works at: http://epublications.bond.edu.au/law_pubs

Part of the Dispute Resolution and Arbitration Commons, and the Family Law Commons

\section{Recommended Citation}

John Wade. (2009) "Negotiating with difficult people".Aug. 2009.

http://epublications.bond.edu.au/law_pubs/255

This Conference Paper is brought to you by the Faculty of Law at ePublications@bond. It has been accepted for inclusion in Law Faculty Publications by an authorized administrator of ePublications@bond. For more information, please contact Bond University's Repository Coordinator. 


\section{Negotiating with Difficult People}

Professor John Wade

Faculty of Law

Bond University

August 2009

\section{Introduction}

This paper firstly suggests a working description of a "difficult person”; secondly, describes outward behaviours of such labelled people; thirdly, sets out five overlapping categories of causes; and finally suggests a toolbox of responses for each "type" of cause.

This topic has a vast foundation in medical, psychiatric, counselling, management, cultural, theological and negotiation literature. ${ }^{1}$

\section{Definitions}

One possible description of a "difficult person" is one who is different to me in beliefs and behaviours. For example:

- talks more; talks less

- beats around the bush; gets straight to the point

- is indirect; is very direct

- focuses on detail; focuses on big picture

- does not listen; listens patiently

- is very emotional; is intensely rational

- is disorganised; is highly organised

- gives priority to the individual; versus the community

- favours top down decision-making: versus grass roots participation and consensus

Because of these differences, I do not feel at ease; my normal patterns of behaviour are not successful; I feel a loss of identity and a failure; I want to avoid or exclude that person; or ridicule that person.

An overlapping but much narrower possible description of a "difficult person" is one who appears (to me and allegedly "independent" others) to be behaving in ways which are detrimental to his/her own best interests and to the interests of his/her community. For example:

- $\quad$ sends long insulting emails

- uses unnecessarily inflammatory language

- arrives at meetings unprepared

- tries to ambush people with new information

\footnotetext{
${ }^{1}$ See best sellers W. Ury, Getting Past No (1991); D.Stone, B Patton, and S.Heine, Difficult Conversations (Penguin:2000); R.J. Lewicki et al, Negotiation (Boston: McGraw Hill, 2006) chs 1718.
} 
- $\quad$ is totally focussed on self-interest ("I need.....”), and is apparently unaware of needs or goals of others

- lies and exaggerates

- cannot identify what is important or a priority in their lives

- spends more time and money on the dispute than it is apparently worth

This narrower version will be used in this paper.

Like most attempted descriptions, this latter one is over-inclusive as it may catch many "difficult” dissenters such as Jesus of Nazareth, Ghandi, William Wilberforce, and Alexander Solzenitzyn. These deviants have been retrospectively recategorised as heroes. At the time, these people were each perceived to be a serious nuisance to their own short term interests and to their dominant communities.

Lawyers have standard expressions to describe "difficult" clients, supporters and lawyers, such as "(s)he is high maintenance”; "(s)he is out of control”; "(s)he is a maniac"; "this will be a long case"; "oh no, not him/her"; "this is a highly conflicted situation”

Conversely, clients describe "difficult" lawyers as "uncaring”; "too busy”; "sharks"; "the main problem in this case"; "unprepared”; "poor communicators” etc.

As a lawyer and mediator, (at a guess) 30\% of my clients initially appear ( at least to me) to be acting contrary to their own interests and they exhibit one or more of the above behaviours. One famous study of lawyer-client conversations identified that the basic circular client-lawyer conversation is: Client: "It's not fair...."; Lawyer: "Yes, but this is how the system works...."; Client: "Oh but that's not fair...."; Lawyer: "Yes but....".

That "Oh but, yes but" conversation usually lasts for about 2 years. Is this "normal", and/or "difficult"?

\section{Narrowing the Definition Twice}

First, what this paper is not about are the "normal" difficulties associated with negotiation. Nearly all negotiations are "difficult" in the sense that there is a loss of control for one or more parties. In fact, the Latin word "negotiare" from which the English word "negotiate" is derived means "stress" and "loss of control". Thus an easy negotiation is arguably a contradiction of terms. Perhaps such should be relabelled "transaction"?

'Negotiation, admittedly is a difficult process as the etymology of the word indicates. Composed of the Latin roots neg (not) and otium (ease or leisure), the word "negotiate" came into the English language in the year 1599. Almost four hundred years later, ... "negotiation" is as fully easeor leisure denying as it was when the Romans conjoined the root words to fashion their "negotiare".,

The normal difficulties or hurdles of negotiation include duelling experts; miscommunication; the last gap; insult openings; outside tribes etc.

\footnotetext{
${ }^{2}$ A. Sarat and W.Felstiner, "Law and Strategy in the Divorce Lawyer’s Office” (1986) 20 Law and Society Rev. 93; Divorce Lawyers and their Clients (OUP: 1995).

${ }^{3}$ A. Lall, Modern International Negotiation (Columbia University Press: New York, 1966) p8; as quoted in H. Astor and C. Chinkin, Dispute Resolution in Australia, $2^{\text {nd }}$ ed (Australia: LexisNexis, 2002) p105.
} 


\section{NEGOTIATION}
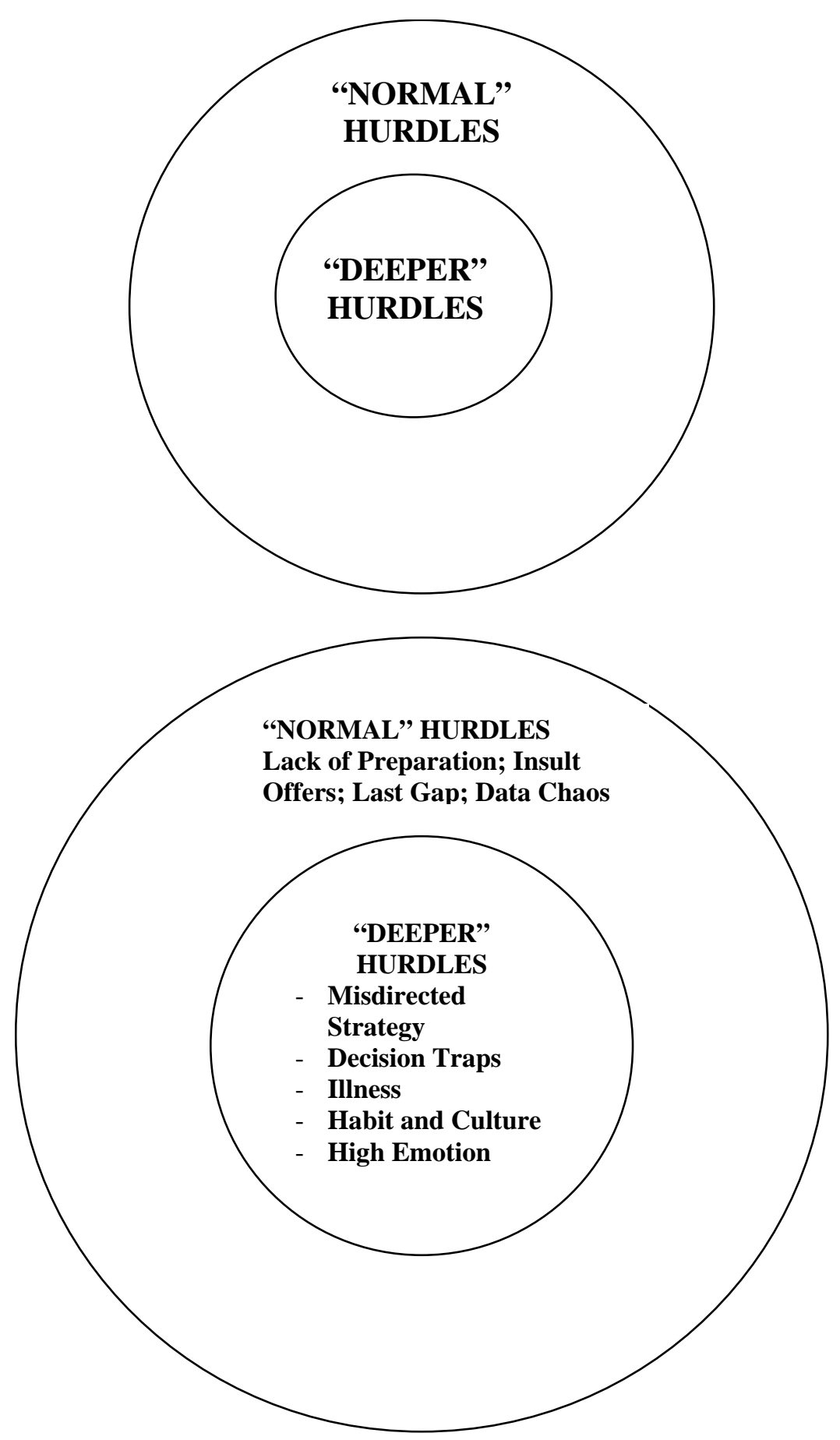

This paper attempts to identify particular layers of challenges beyond but inevitably overlapping with the standard hurdles---namely those people and situations where a client or lawyer appears to be acting against his/her own self interest. 


\section{"Rational Stubborness"}

This paper is also not discussing another category of situations where people stonewall, delay and refuse offers which are arguably in the market range. In this category, the stonewaller is not "irrational" or "stupid". Rather (s)he has open or hidden "rational" reasons to stonewall ... for example, the conflict gives him/her meaning to life and a "cause"; someone else (a friend, legal aid) is paying for the conflict/negotiations; (s)he is hoping that a court will be a theatre of public vindication; or any deal will be interpreted by supporters and tribes as a sell-out. These rational reasons are sometimes hidden behind the unhelpful and ubiquitous smokescreen phrase of "it is a matter of principle". If these motivations become clear, such negotiations should probably be referred to an authority figure or judge. This "need for a judge" is discussed in detail elsewhere. ${ }^{4}$

\section{Causes?}

The causes of "being difficult" are of course complex - perhaps so complex that they are beyond analysis? Most humans reject this black box theory and develop conscious or sub-conscious frameworks or stereotypes in order to understand and respond to difficult people and difficult behaviour. Infinity is reduced to a list of five or seven points. Books are written regularly with recycled and plagiarised wisdom on the 3, 5, 7 or 12 causes; habits; responses to.... God has provided a precedent for this pattern by issuing ten commandments and summarising life guidance into two principles. I now do likewise, with somewhat less authority.

Here are five overlapping causes of the actual or perceived irrationality of clients, tribal supporters, self and other professionals.

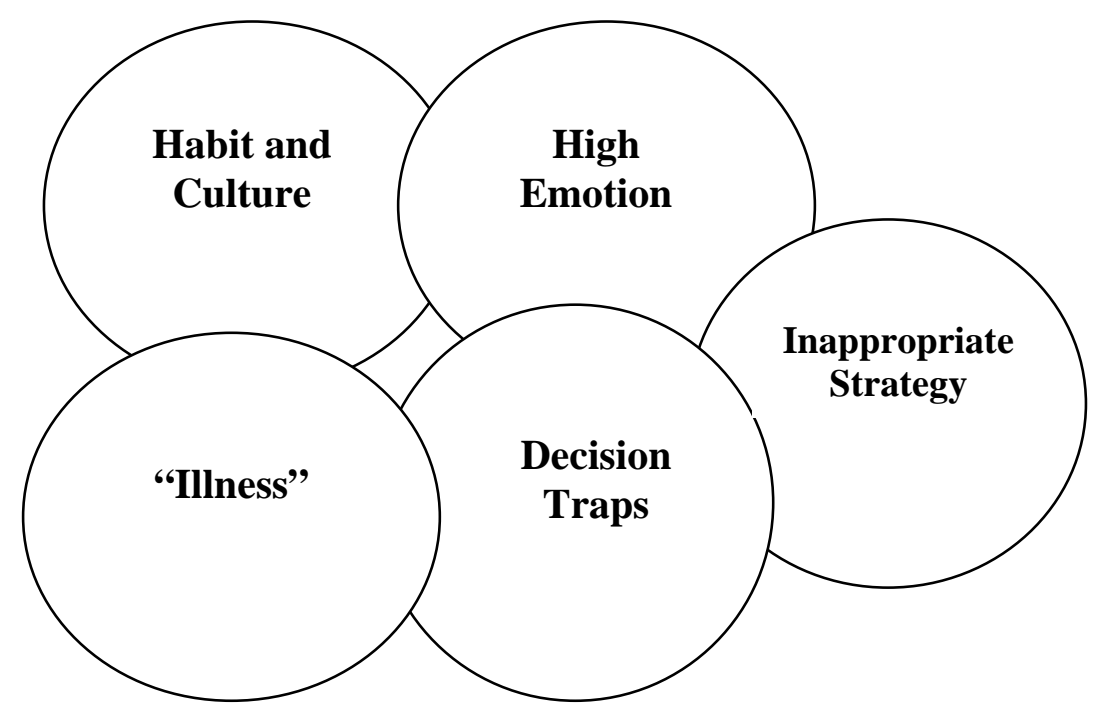

\footnotetext{
4 J H Wade, “Don't Waste My Time on Negotiation and Mediation: This Dispute Needs a Judge” (2001) 18 Mediation Q 259; J H Wade, "Bargaining in the Shadow of the Tribe and Limited Authority to Settle” in A Schneider and C Honeyman, Negotiator's Fieldbook (ABA; 2006); also located at www.epublications.bond.edu.au.
} 
The paper will comment briefly on these five categories, each of which is the subject of many libraries and megabytes. Why bother with all this? To repeat, wrong diagnosis necessarily means wrong treatment.

\section{(1) Habit and Culture}

Some people are very difficult because of habit - "This is the way I have always behaved"; and some due to culture - "The French are very direct" (aka "insulting"); "Lawyers are detail people" (aka "analytical”; or "lose the forest for the trees").

Here are some further examples of challenging habits:

- some lawyers regularly (for 35 years or more!) make insult claims, explore every rabbit hole, and then settle for far less at the door of the court

- clients talk endlessly about "justice" and "fairness" and cannot seem to understand "market price"

- some lawyers/politicians have a habit of using inflammatory language ("win”; "lose"; "right”; “entitlement”). They forget to do a written risk analysis with their pumped-up clients until the door of the court/Bagdad. ${ }^{5}$

What "habits" do you particularly experience for self, clients, other lawyers which make things difficult?

\section{Cultural differences ${ }^{6}$}

One working description of culture is: "patterns of beliefs and behaviours within a group of people”.

"They drive me crazy because...."

- $\quad$ Americans are always in a hurry

- Japanese never get to the point

- $\quad$ Norwegians send juniors to negotiate

- $\quad$ Australians are laid-back and disrespectful

- $\quad$ Lawyers are too aggressive

- $\quad$ Italians are so emotionally expressive that they are unable to make wise decisions

- $\quad$ Men are emotionally unaware

- $\quad$ Canadians are....

etc etc etc

The following two charts provide a glimpse of why negotiating across cultures produces crossed-wires and cross emotions.

\footnotetext{
5 J H Wade, “Systematic Risk Analysis for Negotiators and Litigators” (2001) 13 Bond Law Rev. 462; also http://epublications@bond.edu.au.

${ }^{6}$ For a helpful overview of cultural behaviour, and where you may fit, see R. Lewicki et al, Negotiation $5^{\text {th }}$ ed. 2006, ch 16 .
} 


\section{Some Cultural Differences that Affect Conflict Resolution}

\section{Expressing strong emotions}

- Strong feelings must be gotten out of the way first so negotiation can progress through calm, rational communication. Being objective and reasonable is associated with legitimacy.

- Progress must be made in negotiation before participants can let go of intense expressions of emotion. Strong feelings are associated with legitimacy of a concern.

\section{Trustworthiness of mediator}

- Impartiality is important, therefore someone who is a stranger to all parties is most likely to be trusted.

- Caring and involvement are important, therefore someone familiar who is known and respected by all parties is most likely to be trusted.

\section{Site of Mediation}

- The conflict should be separated from outside influences, therefore a neutral location is best.

- Conflict resolution should take place in the context where the conflict occurs.

\section{Getting to the point}

- It is important not to beat around the bush; identify and discuss the key issues in a conflict quickly.

- It is rude to name problems too quickly; better to spend some time in casual interaction first.

\section{Issue organisation}

- Talk about one thing at a time.

- Deal with several topics at once, or move back and forth between issues.

\section{Saving face}

- Admitting that you have been wrong, or backing down, in unpleasant, but appropriate in some circumstances.

- Losing face is completely unacceptable.

\section{Structure of session}

- Conflict resolution works best when organisation is formal. There should be clear roles, rules, and demarcation of beginning, ending and the stages in between.

- Conflict is best resolved in a climate of informality that resembles casual, social interaction.

\section{Attribution of fault}

- When someone defends themselves against an accusation, it is a sign of innocence; silence signifies guilt. 
- When someone defends themselves against an accusation, it shows they are guilty; to ignore an accusation is a sign of innocence.

\section{Threats}

- Threats represent a real intention to do harm.

- Threats represent a safe way to let off steam without doing real damage. They should not be taken literally.

\section{Function of argument}

- Heated argument escalates conflict and interferes with finding solutions.

- Heated argument is part of the truth-seeking process and helps resolve conflict.

\section{Active listening}

- Nodding, saying “mm hmm," etc, means, "I am paying attention to you."

- Nodding, saying “mm hmm," etc, means "I agree with what you are saying."

\section{Being silent while others discuss}

- Silence is neutral; it simply means someone is not ready to speak.

- Silence represents agreement with what is being said.

- Not speaking when other exchange views is a refusal to help resolve the conflict and is obstructive.

\section{Eye contact}

- It is natural and respectful to look directly at the person you are talking with. Looking away can signify evasion or deception.

- It is natural and respectful to look away while talking with someone. Direct gaze can signify challenge or attack.

\section{Questions}

- Questions indicate interest and genuine concern.

- Questions are a form of attack; it is intrusive to require someone to explain themselves.

[Michel Avery, Friends Conflict Resolution Programs (Philadelphia, 1988)] 


\section{PREDICTABLE CONFUSIONS IN EAST-WEST NEGOTIATION/MEDIATION}

\begin{tabular}{|c|c|c|}
\hline Get to the point & $\longleftrightarrow$ & Be indirect \\
\hline Say what you mean & $\longrightarrow$ & Be indirect \\
\hline Go quickly & $\longleftrightarrow$ & Go slowly \\
\hline "Yes” means “I agree” & $\longleftrightarrow$ & $\begin{array}{l}\text { "Yes" means "I do not } \\
\text { want to offend you" }\end{array}$ \\
\hline Talk about business & $\longrightarrow$ & Talk about family \\
\hline Use first names & $\longrightarrow$ & Never use first names \\
\hline Talk & $\longleftrightarrow$ & Silence is good \\
\hline Sign detailed contracts & $\longleftrightarrow$ & $\begin{array}{l}\text { Sign short contracts, or } \\
\text { just shake hands }\end{array}$ \\
\hline A contract is final & $\longrightarrow$ & $\begin{array}{l}\text { A contract is only an } \\
\text { agreement to talk in } \\
\text { the future }\end{array}$ \\
\hline $\begin{array}{l}\text { Change negotiators at } \\
\text { the table }\end{array}$ & $\longrightarrow$ & $\begin{array}{l}\text { Never change } \\
\text { negotiators }\end{array}$ \\
\hline Anyone can speak & $\longrightarrow$ & $\begin{array}{l}\text { Only the boss should } \\
\text { speak }\end{array}$ \\
\hline $\begin{array}{l}\text { Knowledgeable people } \\
\text { should speak }\end{array}$ & $\longrightarrow$ & $\begin{array}{l}\text { Only the boss should } \\
\text { speak }\end{array}$ \\
\hline I can decide & $\longleftarrow$ & $\begin{array}{l}\text { Many outsiders must } \\
\text { be consulted }\end{array}$ \\
\hline Include lawyers & $\longleftrightarrow$ & Exclude lawyers \\
\hline $\begin{array}{l}\text { Ask many questions to } \\
\text { gather knowledge }\end{array}$ & $\longleftrightarrow$ & $\begin{array}{l}\text { Ask many questions to } \\
\text { show politeness and } \\
\text { gain time to think }\end{array}$ \\
\hline $\begin{array}{l}\text { Argue strengths and } \\
\text { weaknesses }\end{array}$ & $\longleftrightarrow$ & $\begin{array}{l}\text { Avoid such arguments } \\
\text { as someone may lose } \\
\text { respect/“face” }\end{array}$ \\
\hline $\begin{array}{l}\text { Friends must also be } \\
\text { commercial }\end{array}$ & $\longleftrightarrow$ & $\begin{array}{l}\text { Friends must help, no } \\
\text { matter what }\end{array}$ \\
\hline Take some risks & $\longleftrightarrow$ & Avoid risk \\
\hline
\end{tabular}




\section{Example - Habit and Culture}

(a) An elderly farmer had experienced a life of respect and obedience from his wife, four children and the local farming community. He was a self-made man who rarely listened to the advice of others. Now, he was ill and isolated, living alone with the hope that his four estranged children, or angry wife, might visit him. They did not so visit. So he negotiated rigidly on how his $\$ 4$ million estate should be divided between his wife and four children. He predictably resisted advice from his lawyer and the mediator that the division of his estate must reflect the broad guidelines of family law and succession law.

His declining powers of concentration meant that the mediation was adjourned several times while he stonewalled. He died during one of the adjournments and lost everything.

(b) An elderly Sicilian farmer went to court to decide the division of a sugar cane farm between himself, his wife and his only son. He carried a gun and rode around the borders of the farm on a motor cycle. He felt humiliated by his exclusion from the farm, and his loss of respect in the local community.

The judge awarded the farmer $52 \%$ of the value of the farm, but transferred the actual farm to his wife, after a large cash payout to his son for unpaid wages. The farmer, isolated, grieving, stubborn and dangerous appealed and re-opened the negotiations.

His wife eventually agreed to pay him another 5\%; and his son abandoned the cash payout so that they could manage the profitable farm, and be rid of the scorched-earth farmer.

\section{Responses to Habit and Culture?}

Lewicki has suggested that we should engage in self-classification. Do I have low, moderate or high familiarity with the culture (habits) of the "difficult" person? The appropriate response depends upon the accuracy of that self insight.

For example, a person with low familiarity of another culture, should normally-

- Openly admit that he/she unfamiliar with the other's culture ( " I am new to Darwin/ Indonesia/ British Columbia---and look forward to any guidance you can give to me" )

- Study beforehand what practices will or might give unintended offence ( eg see stereotypes - do not flatter Swedes; normally interrupt a French negotiator; do not rush an Indonesian; do not be cooly analytical with a Russian etc)

- Humbly label perceived habits and patterns in advance - "Bill, did you know that you have a reputation for three things? Making wild offers; going down every rabbit hole; and then settling at the door of the court for the right number? "And I seem to have a reputation for my little black book on how other people behave?" "Have you got any suggestions what we should do about our mutual reputations?”

- Bring a respected person who is steeped in knowledge of the local culture and habits, from whom advice and prompting is constantly sought. ${ }^{7}$

\footnotetext{
${ }^{7}$ Lewicki note 1 , ch 16 .
} 
Lawyers usually reflect the above four points of advice and practice by the way they hire local experts in any cross-jurisdictional dispute.

\section{(2) High Emotion}

A close cousin of habit and culture is emotion. Family lawyers, counsellors and mediators worldwide comment that "high emotion" is a normal incident of family conflict. The quiet become hysterical; the talkative tearful; the wise wilful and the strong sad.8

Elisabeth Kubler-Ross’ stages of grief are daily companions of family lawyers/ mediators/counsellors.9

Like international diplomats, family lawyers attempt to manage the emotions of self, clients, the opposition, other lawyers, and the tribal groups of hawks, doves and moderates in the background.

The scars of experience also testify that a steady percentage of "emotional" clients and their cheer squads will later turn on their lawyers with damaging gossip, nonpayment of accounts, legal actions and reports to Law Societies.

Of course, high emotion can be a presenting symptom of many deeper "causes" of being "difficult". ${ }^{10}$

What responses do family lawyers and other professionals use to "manage" clients who are on the emotional roller-coaster? From the limited research done in this area, the most common response appears to be cyclical discussions/lectures/ charts/ storytelling time between lawyer-client on how the client should learn to separate emotion and wise/rational/commercial decision-making.11

One family lawyer the writer worked for used the tactic of "masterly procrastination". Whenever an emotional client "gave him instructions" which he (the lawyer) did not agree with, he would "lose the file". "I am very sorry, we seem to have misplaced your file; my secretary is looking for it.” When the client eventually gave him more "rational" instructions, he would miraculously find the missing papers.

\section{Exercise}

Set out below is a shopping list of possible responses to emotional clients. Please circle the ones you either commonly use, or have seen used by others. Interview your neighbour.

\footnotetext{
${ }^{8}$ A Sarat and W Felstiner, “Law and Strategy in the Divorce Lawyer’s Office” (1986) 20 Law and Society Review 93; Divorce Lawyers and their Clients (OUP: 1995).

${ }^{9}$ E Kubler-Ross, On Death and Dying (1969).

${ }^{10}$ eg S. Hacker, “Dealing With Difficult Clients” Vol 8, No 1 (1992) Australian Family Lawyer provides a psychiatrist's guide to family lawyers of personality disorders such as paranoia, narcissism, histrionics, passive aggression and obsessive compulsion.

${ }^{11}$ See note 8 Sarat and Felstiner.
} 


\section{POSSIBLE MEDIATOR / LAWYER RESPONSES TO THE “EMOTIONAL” NEGOTIATOR / CLIENT}

1. Listen \& empathise

2. Educate \& normalise

3. Long adjournment

4. Short adjournment - tissues and tea

5. Refer to counselling / therapy (with letter)

6. Repression and denial of emotion

7. Ignore emotional cues

8. Persistent return to "practical" matters

9. Professional as knight in shining armour

10. Revert to smaller, interim issues

11. Identify and isolate emotional issues

12. Written report; plus time to reflect

13. Presence of trusted friend

14. Begin "therapy"

15. Counsellor / therapist present at the initial session

16. Ram through an agreement

17. Shuttle diplomacy immediately

18. Start together; then shuttle

19. Cathartic outpouring in one room

20. Confide in other party about emotional agenda

21. Refer to an authoritative decision maker

22. Others?

\section{(3) Inappropriate Strategy}

A working description of a "strategy" is a behaviour consciously chosen with the aim of bringing advantage to self and/or disadvantage to another." Conscious strategies are often difficult to distinguish from subconscious habits and cultural behaviours. This is partly because the latter are explained or rationalised as freely chosen (eg personal insults; yelling; arriving late; hiding information; lying) rather than as subconscious patterns or wiring.

"Difficult people" sometimes use strategies to discomfort others or comfort themselves. Usually they have experienced considerable short-term "success" during their lives with these strategies. However, an accumulation of reputation for inappropriate "gamesmanship" often eventually isolates those players.

What are common consciously chosen strategies?

- Yelling at and insulting others.

- Fixing on a price well above or below the "going-rate" and hoping that this will drag others towards that number. 
- Hiring prostituted experts such as valuers, lawyers, psychologists.

- Feeding experts garbage-in so that they produce helpful garbage-out.

- Drowning others in paper and data.

- Moving assets and/or children to another remote country.

- Sending junior people to meeting.

- Adjourning meetings and hearings.

- Adding-on last minute demands (“There's one more thing. We want costs, Christmas Day; the Van Gogh sketch” etc.)

- Seeking to split a team by embarrassing supporters (business partners; new spouses; bankers) with adverse publicity and subpoenae.

- Sending prematurely “threatening” correspondence (“I’m right; you're wrong; demand; deadline; consequence”).

- Attempting to achieve public humiliation and the moral high ground. (eg "That's a racist/sexist/insensitive comment”.)

- Collecting a war chest and comfortable accommodation before making claims.

- Pleading poverty: "I do not have any money to pay you until this is all over". etc.

These common strategies are arguably appropriate if they regularly achieve "success". Conversely, based on the definition being used in this paper, difficult people choose to use these strategies in situations where they cause serious damage to themselves.

\section{Example of Counter-Productive Strategies}

A mediation was arranged between a husband and a wife to divide $\$ 11$ million. The husband failed to produce asset lists with supporting documents as required by the mediator's contract. He then purported to cancel the mediation. The mediator immediately sent him an email account for belated cancellation. The husband reinstituted the mediation instantly!

The mediation contract required both lawyers to disclose their advised range of percentages confidentially to the mediator; and that their ranges be divided by a $15 \%$ gap. Both lawyers did so. The ranges were identical (25\% - $40 \%$ to the wife). At the mediator's request, each lawyer disclosed the identical range advice to the other.

However, the husband insisted on starting his offers to the wife at zero. "This is the way I have always negotiated.” Despite pressure from his own lawyer, and from the mediator, he insisted that zero (an "insult" offer) was his starting bid.

Therefore, the mediator terminated the mediation, without giving reasons to the wife and her impatient team. However, the wife smiled knowingly at the mediator's silence. At the intake meeting with the mediator she had been asked the standard intake question "What could go wrong at the mediation?" She answered prophetically "My husband in his business has a history of stonewalling with silly offers until the door of the court - then he caves in”. His dominant strategy had become over-used and identified.

Footnote: The wife had been prepared to settle for $25 \%$ at the mediation for a number of "commercial” reasons - at the bottom of her agreed market range. The husband's lawyer withdrew due to his client's tired strategy. The husband went to a full hearing, against his second lawyer's advice, and the wife was awarded $40 \%$ plus her full costs. 


\section{Responses?}

There are four basic responses to "strategies" in negotiation----with many subtypes of each of these categories.

(1) Ignore the behaviour when a person makes an insult offer; throws a tantrum; plays good cop-bad cop etc. Just pretend that nothing happened. " Now how would you like to proceed?”

A modified version of silent ignoring is spoken ignoring. " I am going to pretend that that I did not hear what I think you just said. " My hearing and sight are very poor today”. "I am not even going to mention that offer to my clients"; "Did you find that number in a telephone directory?"

(2) Label the behaviour and ask what can be done about it. For example- "Mary, you have just made an offer with zero market support, what do you expect me to do now?”

"Dave, you and Rhonda look like the old good-cop bad-cop routine. What would you like us to do about that?"

"What do you want me to do when you raise your voice and wave your arms?”

"We have the three usual choices-ignore you, leave, or bring along someone who does the same? Which one would you prefer?

"Can I suggest for today that we put aside personal blame and try to find ways to avoid these incidents in the future?"

\section{(3) Take a Break.}

For example- "We would like to take a break for a few minutes. We will be right back"

"Given what is happening, we would like to take a break---and Joe ( the perceived moderate), could I talk to you for a moment?”

During the break, attempts can be made to diagnose what is happening, and what responses might be appropriate to the perceived strategic behaviour.

\section{(4) Use strategic responses}

This response needs some caution as it is very easy to react to perceived and annoying strategic behaviours. ("They deserved it for being so stupid”). Nevertheless, non-emotional and theatric responses can occasionally be very effective. For example---selective screaming; employing aggressive bad cops on very short leashes; making insult offers at the other end of the spectrum in response to insult offers; withdrawing all previous offers; making time limited or exploding offers; declaring that a meeting is terminated etc. 


\section{Exercise}

Set out three examples of strategic behaviour you often see; and three common responses to those behaviours.

\section{(4) Illness}

Illness is a difficult concept to describe as the dividing lines between "health", "genius", "normalcy" and "sickness" are matters of degree. At the extremes, physical or mental illness are arguably apparent.

"Illness" is an important, though controversial, diagnosis of the possible/probable causes of "difficult" behaviour. This is because -

- Mental illness, anxiety and depression are endemic in industrialised Western societies. For example, in Australia, repeated studies have found that over 20\% of practising lawyers suffer from "serious depression". ${ }^{12}$

- Illness is sometimes used as an excuse for irresponsible behaviour. "The devil made me do it - hit the children; gamble the wages; forget to pay the taxes".

- The intensity of loss which normally follows from marriage separation is sometimes described by family lawyers as a form of "temporary insanity". "Part of my job is to hinder my clients from making foolish decisions while passing through the grief process.”

- Actual or exaggerated illness is sometimes used as a conscious strategy ("I cannot attend that meeting"; "I am unable to go back to work"; "the children are depressed because of your behaviour"; "I have enhanced future needs due to my condition”).

- It is easy to label another person as "crazy", "obsessive” or "insane” when their insights into my own behaviour are profound and embarrassing. Our history has many dark chapters reflecting this pattern of medical persecution of the insightful.

Nevertheless, despite the above challenging edges, in Australia and probably elsewhere there remains an increasing core of clients and colleagues who suffer from various mental illnesses, alcoholism and/or drug addiction (“comorbities”). They exhibit behaviours including emotional flatness, mood swings, inability to concentrate or make decisions, paranoia, violent outbursts, loss of motivation and joy, diminishing care about food, friends, health or exercise. They self medicate with booze and barbiturates.

Judges at all levels of courts, from Magistrates to High Court are also struggling with this expanding class of casualties from modern industrialised life. An increasing number of mentally ill people are appearing at registry counters, in interim or final hearings, with or without legal assistance. In 2009, the Chief Justice of the Family Court of Australia commented:

\footnotetext{
${ }^{12}$ N Kelk et al, Courting the Blues: Attitudes Towards Depression in Australian Law Students and Legal Practitioners (University of Sydney: 2009).
} 
"Over the last decade in particular it has become apparent that:

- allegations of family violence are being raised more frequently

- multiple allegations are being made in the course of one case

- allegations are being made by both parties against each other

- the alleged behaviour is more concerning

- allegations of violence are often accompanied by allegations of substance abuse and poor mental health"13

\section{Responses?}

What responses are available to "illness" in clients and colleagues?

None of these are particularly satisfactory. Nevertheless, some conscious strategic responses are better than muddling through. These responses may assist the client to make wiser decisions; help any agreement to stick for longer; and provide some evidentiary protection for a lawyer when a client later complains about duress or lack of informed consent.

1. Refuse to act for or negotiate until the client gives written permission for the skilled helper to talk to medical practitioners or psychologists who have worked with the client in the past.

2. Refuse to act for or negotiate until the client/colleague has been to a psychologist and that expert has reported back with a diagnosis and strategy.

3. Insist that any negotiations will require the presence of a friend or selected relatives, and that the lawyer have permission to speak to those supporters beforehand.

4. Set up any meetings in the time and environment which the client suggests reduces stress.

Example: A female mediation client suffered from delusional beliefs about her wealth, and followed a pattern of blaming others for her irresponsible management of money. She said that she could make decisions if a mediation took place where she could take regular naps nearby, and if a trusted friend could sit with her. This environment was set up; the trusted and wise friend was met at an intake session; a structured settlement was reached which controlled the flow of money to her. She was momentarily content, but predictably turned on both her friend and her lawyer with letters of blame.

\footnotetext{
${ }^{13}$ Diana Bryant, Chief Justice, Family Court of Australia, "Family Violence, Mental Health and Risk Assessment in the Family Court of Australia” (QUT, 2009) at 18.
} 
Example: A male mediation client had a history of smoking marihuana. The result was that he could not concentrate, and managed any meeting by glazing over, or quickly agreeing and then reneging. His aggressive and trusted barrister was invited to attend, and agreed to give signals whenever his client began to "space out". An adjournment signal was given by that barrister, and the client was taken downstairs to be pumped up with cigarettes and coffee (about every 15 minutes in two five hour meetings). Initial agreements were quickly breached. However, the wife's lawyer discovered at those meetings that the male was deeply attached to his sailing boat and overseas travel. She obtained a quick (and lucky) injunction to limit use of both. This deprivation of toys led the male to concentrate in subsequent meetings over the phone. His aggressive lawyer threatened his own client with isolation, and he signed consent orders which were immediately taken to an awaiting registrar for approval.

5. Tell the client that it is too difficult to negotiate with him/her, and refer the dispute to an unfortunate judge to manage. This is no doubt a temporary passing of the buck, and may avoid the expense and frustration of long negotiations; and predictable reneging on the agreement; and complaints to the Law Society for undue pressure to settle. Obviously, a judge may continue the buck passing and refer the client back to the lawyers to "fix" the dispute in one or several mediations.

\section{(5) Decision Traps (aka "Cognitive Heuristics")}

There is a fifth cause for people being particularly difficult. This is known as the bundle of "decision traps" which subconsciously afflict all human beings. Although well known in Psychology 101, these formal insights have only filtered across to closeted legal thinking in the last decade. Bitter experience has taught some lawyers to distrust self and others, without reading the studies which justify such distrust. ${ }^{14}$

The school of hard knocks has taught some negotiators about the constant fallibility of human decision-making. This wisdom is then reflected in the ubiquitous phrases:

- “On my understanding”

- “Correct me if I’m wrong..."

- “Am I missing something..."

- "Only fools rush in..."

- "What assumptions are we making here?"

- "I've been wrong many times before, so..."

- “On what evidence do you base that statement..."

A decision trap is a short rule of life/thumb which assists us all to manage the complexity of decision-making. Life is so complex that it is essential to have such short-cuts as no-one has the ability to collect and then process all relevant information----despite the mythology and rhetoric of legal education about "full" discovery of "all relevant" facts. These short cuts serve us well normally, but when applied mechanically, they produce profound stupidity.

\footnotetext{
${ }^{14}$ Hammond et al, Smart Choices (1999); Cordelia Fine, A Mind of Its Own (Australia: Allen \& Unwin, 2005); Lewicki (2006) note 1 at pp 144-152.
} 


\section{DECISION- MAKING SHORTCUTS AND TRAPS (FOR NEGOTIATORS AND OTHERS)}

* The ANCHORING TRAP: Overrelying on First Thoughts

* The SUNK-COST TRAP (ENTRAPMENT):Protecting Earlier Choices

* Mythical FIXED -PIE Beliefs

- The STATUS-QUO TRAP: Keeping on keeping on

* The CONFIRMING EVIDENCE TRAP: Seeing what you want to see

* The FRAMING TRAP: Triggering a premature answer with the Wrong Question

* EASILY AVAILABLE INFORMATION TRAP: "What an impressive chart!"

* The WINNER'S CURSE: "Perhaps we could have done better?"

* The OVER CONFIDENCE TRAP: Being too sure of your knowledge and ability

- The BASE-RATE TRAP (The Law of Small Numbers):Neglecting Relevant Information

- SELF-SERVING BIAS: Environment versus Personality

IGNORING OTHERS' INTERESTS AND PERCEPTIONS: "Let's Get Down to Business"

* REACTIVE DEVALUATION: Ridiculing "Opposition's" Ideas and Behaviour 


\section{Example}

A woman aged 34 years had lived in a 5 year relationship with a violent and successful entrepreneur.

After a violent incident, she left and "took" $\$ 600,000$ in cash from the home. The male had another $\$ 5.5$ million in assets (all acquired within the last 5 years), and was engaged in nine disputes across Europe with creditors to whom he allegedly owed money.

The woman went to see lawyers who advised her that she was entitled to between $30 \%-40 \%$ of the asset pool. The male went to see lawyers who advised him that she was entitled to between $5 \%-11 \%$ of the property pool. The male's lawyers produced three case precedents which allegedly supported this 5\%-11\% range. Thus the monetary gap between them was at least $\$ 1.2$ million. Each paid $\$ 125,000$ to their lawyers to cover initial fact searching skirmishes.

The female and her expert legal team fell into a number of decision traps. What do you predict these would be?

\section{Responses to Decision-Traps?}

What are the possible responses to perceived decision traps in self, clients and others? This is a challenge as most intelligent people have not even heard about their own defective wiring, and are over-confident of their rationality.

Awareness is not enough; the mistakes persist.

The only glimmer of hope seems to be systematic written preparation --- for example individual and group answers to structured questions such as:

- What are my/their short-term/long-term goals?

- Why have we not been able to settle this dispute so far?

- What interventions may assist?

- What could go wrong at the next meeting/interchange of emails?

- What are the life/commercial/legal risks to me if there is no agreement for another 2 years?

- How many different verbal formulae are available to "frame" the questions to be answered at the negotiation?

As negotiators tend to have over-confidence and sunk costs, such structured self examination is culturally abnormal in law offices. ${ }^{15}$ Thus the introduction of a courtjester, or wise elder, or "new team" at a later stage of the negotiation may lead to such a structured fresh analysis.

\footnotetext{
${ }^{15}$ See J.H. Wade, "Systematic Risks Analysis for Negotiators and Litigators: But You Never Told Me It Would be Like This” (2001) 13 Bond Law Rev. 462; also www.epublications.bond.edu.au.
} 


\section{Conclusion}

This paper has created five overlapping categories of beyond-your-average-gardenvariety of "difficult" people. It is submitted that a humble diagnosis of causes should be attempted, shared and modified well before commencing negotiations with the allegedly or known to be "difficult person".

This is because wrong diagnosis leads to wrong response. Sadly, there is no allpurpose spanner in the response tool box.

Bringing a wise friend is the closest to an all-purpose response and is the one the writer uses regularly in commercial and family mediations. Unfortunately, some difficult people have a shortage of friends, much less wise ones.

My hope is that you practise diagnosis, add two or three responses to your existing toolboxes, and then share with colleagues the spectacular and minor successes and failures which follow. 